ПРОСКУРЯковА Е. А.

СУБЪЕКТИВНАЯ ОЦЕНКА МЕСТ ЖИТЕЛЯМИ САНКТ-ПЕТЕРБУРГА

Российский психологИчЕский жУРнАл, 2020, Т. 17, № 2, 36-57. doi: 10.21702/rpj.2020.2.3

ОБЩАЯ ПСИХОЛОГИЯ, ПСИХОЛОГИЯ ЛИЧНОСТИ, ИСТОРИЯ ПСИХОЛОГИИ

УДК 159.9.07 doi: $10.21702 /$ rpj.2020.2.3

Оригинальная научная статья

\title{
Субъективная оценка мест жителями Санкт-Петербурга
}

\author{
Елизавета А. Проскурякова \\ Санкт-Петербургский государственный университет, г. Санкт-Петербург, Российская Федерация \\ E-mail: eliz.proskuryakova@gmail.com \\ ORCID ID: https://orcid.org/0000-0002-7565-0812
}

\begin{abstract}
Аннотация
Введение. Коморортное место найти сложно: колмективные преАставления о АОлЖном комфрорте разнятся с инАивиАуальными ощущениями; оценка места имеет в основе ощущения инАивиАуальные и колмективные представления. Ощущения заменяются преАставлениями, в результате определение и трансляция ощущений затрудняются. Проблема-опрелеление ощущений, отАеление от представлений; решение -исследование оценок места и поиска влияющих фракторов. Гипотеза: предикторами оценок яв^яются темперамент и самоощущение; Аополнительная гипотеза: синтезирующая ощущения от места - категория «приятности). Новизна - в комп^ексном эмпирическом исслеАовании со станАартизированными психологическими методиками одновременно с нейродевайсом, выхоАом из ^аборатории на улицу; объеАиняющим элементом служит авторский опросник «оценки мест».
\end{abstract}

Методы. Приведены Аанные о субъективной оценке мест, фокторном и регрессионном анализе этих фракторов. ПреАикторы: балмы респонАентов по опросникам САМОА^ Э. Шострома, МИС С. Р. Пантилеева, «Суверенность психологического пространства» С. К. НартовойБочавер, тест на темперамент ЕРІ Г. Айзенка (вариант В) и Я. Стреляу, тест «ИнАекс жизненной УАовлетворенностил. Проверка состояния переА исслеАованием-опросник САН, место ассоциировалось с цветом из набора Аюшера, обработка по методике ЦТО А. М. ЭткинАа. Выборка: 31 житель Санкт-Петербурга, срелний возраст 26,68 ^ет (женщин 56,7\%, мужчин 43,3\%), на маршруте из 4-х мест протяженностью 1,5 км на Васильевском острове.

Результаты. Распределение корреляций в зависимости от новизны места и активности свидетельствует о влиянии параметров в субъективном выражении на оценку. Составлены регрессионные уравнения Аля оценок, продемонстрировано влияние преАикторов самоощущения и темперамента на оценку места.

ОбсужАение результатов. Категории «притягивающее» и «отталкивающее» опрелелены как совокупные, составлены фрормулы: место оценивается притягивающим, если комфрортное и уютное, а отталкивающим - если нечистое и вызывает тревогу. ПреАложены рекоменАации бывать чаще в новых местах с наименьшей активностью - так ^егче осознать ощущения.

\section{КАючевые слова}

оценка места, чувство места, приятность места, ощущение пространства, городское пространство, самоощущение, суверенность психологического пространства, темперамент, инАекс жизненной уАовлетворенности, кол^ективные представ^ения 
ПРОСКУРЯКОВА Е. А.

СУБЪЕКТИВНАЯ ОЦЕНКА МЕСТ ЖИТЕЛЯМИ САНКТ-ПЕТЕРБУРГА

РосСИЙСКИЙ пСИХОЛОГИЧЕСКИЙ ЖУРнАл, 2020, Т. 17, № 2, 36-57. doi: 10.21702/rpj.2020.2.3

ОБЩАЯ ПСИХОЛОГИЯ, ПСИХОЛОГИЯ ЛИЧНОСТИ, ИСТОРИЯ ПСИХОЛОГИИ

\section{Основные положения}

$\checkmark$ Аля облегчения пребывания человека в современном мегаполисе орормируется механизм облегченной оценки мест по аналогии с процессом категоризации и атрибутирования, что приволит к формированию представлений о месте;

$\checkmark$ преАставления о месте могут быть инАивиАуальными и колмективными;

$\checkmark$ на фоормирование инАивиАуальных ощущений в момент присутствия в месте оказывают возАействие активность среды и субъективное ощущение новизны, темперамент и самоощущение;

> совокупное ощущение места наиболее полно представляется человеком в категориях «притягивающего» и «отталкивающего».

\section{Для цитирования}

Проскурякова, Е. А. (2020). Субъективная оценка мест жителями Санкт-Петербурга. Российский психологический журнал, 17(2), 36-57. doi: 10.21702/rpj.2020.2.3

Дата получения рукописи: 20.12.2019

Дата окончания рецензирования: 13.06 .2020

Дата принятия к публикации: 15.06.2020

\section{Введение}

Нахождение в стрессовой ситуации постоянной модернизации городской среды провоцирует человека к постоянному восприятию. Данная ситуация энергозатратна для мозга, поэтому, мы предполагаем, формируются механизмы, облегчающие данную задачу. Результатом восприятия среды становятся детальный образ и оценка места. Образ места отвечает на вопрос «Какое место?» и представляет собой изображение. Оценка места отвечает на вопрос «Какое место?», основываясь на вопросе «Каково человеку здесь?» (индивидуальные ощущения и представления) и «Каково человеку должно быть здесь?» (коллективные представления). Их и предстоит изучить, что возможно посредством проведения исследования по вопросу оценки мест.

Предполагается, что в момент воспоминания и в ситуации отдаления человек в качестве оценки места транслирует усвоенные в обществе обобщенные ощущения, по сути - коллективное представление о месте. В момент непосредственного ощущения места человек может сконцентрироваться на собственных ощущениях, легче это будет сделать в месте с субъективно высоким ощущением новизны и минимальной активностью объектов.

«Самым общим способом работы с социальной информацией является процесс категоризации - отнесение каждого нового воспринимаемого объекта к некоторому классу подобных уже известных ранее объектов» (Андреева, 2000, с. 99). По сути, коллективный образ места - максимально упрощенная единица информации (категория или несколько категорий), состоящая из множества мнений об этом месте. «Ее генеральная функция - как раз такое упорядочивание и упрощение информации» (Андреева, 2000, с. 100). Приписывание новых качеств местам для полного соответствия коллективному образу происходит по аналогии с процессом атрибуции. В итоге мы получаем механизм, облегчающий затраты на энергию, но не дающий познавать места непосредственно через индивидуальные ощущения, что затрудняет гармоничное развитие личности. Мы приходим к выводу, что этот механизм полезен, 
ПРОСКУРЯКОВА Е. А.

СУБЪЕКТИВНАЯ ОЦЕНКА МЕСТ ЖИТЕЛЯМИ САНКТ-ПЕТЕРБУРГА

Российский психологИчЕский жУРнАл, 2020, Т. 17, № 2, 36-57. doi: 10.21702/rpj.2020.2.3

ОБЩАЯ ПСИХОЛОГИЯ, ПСИХОЛОГИЯ ЛИЧНОСТИ, ИСТОРИЯ ПСИХОЛОГИИ

но важно изучить его и понимать, каким образом возможно снижение его эффективности в пользу индивидуального познания пространства и конструирования собственного мира.

\section{Постановка проблемы}

Современный человек, в процессе познания своей индивидуальности для последующего проявления своей аутентичности, становится более активным действующим лицом. Одним из способов подобной трансформации личности является процесс осознанного ощущения места в городской агломерации - через познание места человек познает себя, однако данный процесс недостаточно изучен. Но быть в контакте с собой и анализировать новые ощущения современному жителю мегаполиса затруднительно ввиду постоянно изменяющейся среды, требующей стремительной адаптации к ней.

Между тем современные исследователи констатируют низкую удовлетворенность местом проживания, что оказывает негативное влияние на удовлетворенность жизнью. В частности, в упомянутой работе из Ульяновска говорится о $40 \%$ людей, частично или полностью неудовлетворенных местом проживания (Шиняева, Ахметшина и Клюева, 2017).

Вопрос комфорта человека в городской среде уже поднят. О чувстве места в связке с понятием саморегуляции было упомянуто еще в прошлом веке (Korpela, 1989). Множество исследований на тему ощущения человека в городе проводились и после (Al-barrak, Kanjo, \& Younis, 2017; Al-Barrak \& Kanjo, 2013; Newman \& Brucks, 2016). Зачастую эксперименты на данную тематику проводятся с использованием измерительных приборов (замер пульса, ЭЭГ), но в лаборатории путем демонстрации изображений городской среды, что делает ситуацию искусственной и не дает добиться максимального эффекта воздействия среды: нет ощущения ее активности, как в работе К. Ньюмана. Остальным представленным рядом ученых были проведены исследования в студенческом городке с использованием переносного ЭЭГ в виде нейродевайса (ободка с электродами): эксперимент помог респондентам ощутить среду в полной мере, но люди смогли оставить информацию об ощущении пространства только в виде последовательности данных о нейронных импульсах, без словесного субъективного оценивания места. В эксперименте мы попробовали учесть это обстоятельство: провели эмпирическое исследование с использованием нейродевайса, учитывающее 2 показателя (возбуждение и расслабление, основано на волнах мозга), на реальной улице, с проверкой состояния перед прохождением по САН, прохождением стандартизированных методик заранее и проведением интервью и оценки каждого места в момент пребывания в нем.

Также зарубежными учеными (Ellard, 2015; Glaeser, 2011; Hall, 2014; Keedwell, 2017; Montgomery, 2015) представлены работы в контексте нахождения комфортного состояния в современном городе - в последние несколько лет объем литературы на эту тему увеличился многократно, что также подтверждает наличие запроса от общества и важность изучения данной темы.

В последнее время проводится множество исследований, стимулирующих человека к ощущению уже ставшего привычным городского пространства в режиме «здесь и сейчас». Так, например, в индийском городе Калькутта М. Мукхерджи описывает, как в 2018 г. была установлена камера на здании театра, снимающая 360-градусное видео непрерывно в течение 10 дней - запись транслировалась для жителей, а затем была использована в мастер-классах и постановках для сознательного изменения точки внимания при нахождении в городском пространстве (Mukherjee, 2019). 
ПРОСКУРЯКОВА Е. А.

СУБЪЕКТИВНАЯ ОЦЕНКА МЕСТ ЖИТЕЛЯМИ САНКТ-ПЕТЕРБУРГА

РосСИЙСКИЙ пСИХОЛОГИЧЕСКИЙ ЖУРнАл, 2020, Т. 17, № 2, 36-57. doi: 10.21702/rpj.2020.2.3

ОБЩАЯ ПСИХОЛОГИЯ, ПСИХОЛОГИЯ ЛИЧНОСТИ, ИСТОРИЯ ПСИХОЛОГИИ

Кардинально другой подход фокусируется на определенном аспекте, например, как восприятие качества ближайших зеленых насаждений влияет на общую удовлетворенность жизни в городе. Именно понимание индивидуальных ощущений может значительно способствовать принятию более эффективных решений и сократит разрыв между необходимыми и предлагаемыми проектами по проектированию окружающей среды, считают Hadavi, Kaplan, \& Hunter (2018).

Очень перспективными выглядят исследования Kasemets, Rammo, \& Palang (2019) в Эстонии, в бывшем военном районе и бывшем садоводческом кооперативе (они были превращены в постоянные жилые помещения), ставящие акцент на исследовании чувства места через создание сообществ и общинные механизмы - оно показывает на разницу между социальным и экологичным чувством места.

В Иране Zabetian \& Kheyroddin (2019) работали над темой теплового комфорта как фактора чувства места в городских пространствах: гипотеза о связи этих явлений была доказана, и предложены стратегии для улучшения тепловой адаптации.

В том же году коллеги с Н. М. Ардоин из Стэнфорда изучали, как развивается чувство места и что оно собой представляет, как меняется в современном быстро урбанизирующемся, глобализирующемся мире. По результатам респонденты, проживающие в городских районах, оценили свою связь с биофизическими аспектами места проживания ниже, чем респонденты, проживающие не в городских районах. Выводы свидетельствуют о важности поощрения концептуализации места в более широких географических масштабах и, в частности, поддержки представлений о городских пространствах, простирающихся за пределы городских границ. Авторы также призывают поддерживать более активное взаимодействие с городской природой, особенно среди жителей городских районов (Ardoin, Gould, Lukacs, Sponarski, \& Schuh, 2019).

Наконец, в Турции Şentürk \& Gülersoy (2019) рассматривали, как жители устанавливают связь с пространством, т. е. исследовали чувство принадлежности к жизненному пространству, что близко к пониманию понятия и в России. В этой работе предполагается, что увеличение продолжительности жизни индивида в определенном месте оказывает положительное влияние на эти отношения. По этой причине исследование основано на взаимодействии жизненного времени, чувства принадлежности, городской идентичности и сохранения городской среды.

Как можно видеть, исследования чувства места на данный момент весьма актуальны, проводятся в разных частях света и связывают проявление понятия с множеством параметров. В пространстве российской науки словосочетание «чувство места» проявило себя (наряду с параметром «привязанность к месту») как «базовые параметры человеческого взаимодействия и самореализации»: по сути, эти понятия операционализируют отношения человека и пространства его обитания (Резниченко, 2014). Автор упомянутой статьи отмечает активную стадию исследований данной тематики в течение двадцати лет до настоящего времени, причем публикации разрозненны по содержанию, а все обзоры представлены в англоязычной литературе: М. Е. Паттерсон и Д. Р. Вильямс в 2005 г., Л. Сканнел и Р. Гиффорд в 2010 г., С. К. Тринтелман в 2009 г. В русскоязычной литературе термин «чувство места» нельзя считать столь же распространенным, как за рубежом. В большей степени популярно исследование концепта «жизненное пространство личности» (Дмитриева, 2013; Куницына и Юмкина, 2012; Нартова-Бочавер, Бочавер и Бочавер, 2011), где подразумевается исследование актуального состояния этого пространства и отношения к нему, концепт связывается с понятиями дома и семьи. 
ПРОСКУРЯКОВА Е. А.

СУБЪЕКТИВНАЯ ОЦЕНКА МЕСТ ЖИТЕЛЯМИ САНКТ-ПЕТЕРБУРГА

Российский психологИчЕский жУРнАл, 2020, Т. 17, № 2, 36-57. doi: 10.21702/rpj.2020.2.3

ОБЩАЯ ПСИХОЛОГИЯ, ПСИхОЛОГИЯ лИЧнОстИ, ИСТОРИя ПСИхОЛОГИИ

Теоретические обзоры в рамках темы восприятия городской среды широко представлены в двух основных отечественных публикациях (Габидулина, 2012; Штейнбах и Еленский, 2004), а также изданы обзоры недавних экспериментов (Дробышева и Журавлев, 2016; Журавлев и Купрейченко, 2012).

В качестве основы в теме самоощущения и осознанного подхода использовались теоретические разработки Елисеева (2000), Леонтьева (2013), Знакова (2016), Моросановой и Ароновой (2007).

\section{Цели и гипотезы исследования}

Цель исследования: проверить, какие именно личностные свойства и особенности выступают предикторами «субъективных оценок мест».

С исследовательской точки зрения представляется важным проанализировать характер оценивания окружающей городской среды современным человеком, вынужденным постоянно адаптироваться к новым условиям, и разработать рекомендации по более комфортному нахождению в среде.

Гипотеза исследования: оценка места современного жителя мегаполиса будет основываться на активности среды, но ее точность будет зависеть от степени привычности места. В качестве факторов, оказывающих влияние на оценку места, будут темпераментные особенности (экстраверсия, нейротизм, торможение, возбуждение, устойчивость, показатели с нейродевайса), а также выраженность аутосимпатии. Гипотеза основана на выводах предыдущего исследования, где шкала САМОАЛ «аутосимпатия» выступала предиктором при оценке мест. В новом эмпирическом исследовании для проверки гипотезы об ощущении был использован опросник МИС С. Р. Пантилеева, что позволило проверить вопрос о связи с самоощущением более широким образом.

Под местом понимается «открытая система, границы которой определяются полем функционирования субъекта» (Резниченко, 2014, с. 15).

Дополнительная гипотеза: категория «приятности» является категорией, синтезирующей все ощущения человека от места.

\section{Методы}

Проведено эмпирическое исследование, включающее в себя измерение субъективного отношения к местам в городском пространстве жителями Санкт-Петербурга с помощью авторского опросника в момент нахождения в месте, а также прохождения этими же респондентами перед этим стандартизированных опросников (САМОАЛ Э. Шострома, МИС С. Р. Пантилеева, «Суверенность психологического пространства» С. К. Нартовой-Бочавер, тест на темперамент EPI Г. Айзенка (вариант В) и Я. Стреляу, тест «Индекс жизненной удовлетворенности» в интернет-форме с помощью ресурса Google Forms) (Зоткин, 2007; Калина, 1998; Нартова-Бочавер, 2014; Никишина и Василенко, 2004; Райгородский, 2001). Ссылка отправлялась индивидуально, респонденты перед этим были проинструктированы о процедуре заполнения. Среди горожан были выбраны люди (31 человек) с опытом проживания более трех лет, средний возраст которых составлял 26,68 лет. В процентном соотношении представлено такое распределение гендера: женщин 56,7\%, мужчин 43,3\%. Маршрут представлял собой путь по Васильевскому острову и включал четыре разнообразных по темпу функционирования среды места, которые испытуемые оценивали поэтапно и индивидуально после нахождения в месте 
ПРОСКУРЯКОВА Е. А.

СУБЪЕКТИВНАЯ ОЦЕНКА МЕСТ ЖИТЕЛЯМИ САНКТ-ПЕТЕРБУРГА

РосСИЙСКИЙ пСИХОЛОГИЧЕСКИЙ ЖУРнАл, 2020, Т. 17, № 2, 36-57. doi: 10.21702/rpj.2020.2.3

ОБЩАЯ ПСИХОЛОГИЯ, ПСИХОЛОГИЯ ЛИЧНОСТИ, ИСТОРИЯ ПСИХОЛОГИИ

около 5-ти минут. Протяженность маршрута составляла 1,5 км. Исследование проводилось в течение недели в марте, чтобы максимально исключить влияние погоды, и преимущественно в течение светового дня с одинаковым набором инструкций и содержанием опросного листа, с уточнением состояния респондента с помощью опросника САН (заполнялся перед прохождением маршрута), а также с одинаковым путем прохождения маршрута.

Оценка мест происходила путем отметки цифры от 1 до 10 на бумажном бланке сразу после пребывания в этом месте (в течение 5-7 минут) по следующим 18 параметрам: «приятное», «угнетающее», «спокойное», «отталкивающее», «суетное», «безопасное», «уютное», «чистое», «культурное», «просторное», «активное», «с ощущением новизны», «светлое», «любимое», «престижное», «комфортное», «тревожное», «притягивающее». В конце прохождения места респондент выбирал один цвет из 8 карточек Люшера для использования в тесте ЦТО А. М. Эткинда (Эткинд, 1983). В конце маршрута респондент также ранжировал последовательность цветов от наименее неприятного до наиболее неприятного. В процессе обработки была создана переменная «опосредованный цвет» с помощью преобразования номера цвета, ассоциированного с определенным местом, в номер относительно последовательности цветов по признаку неприятности. Например, место «1. Пешеходная линия» было ассоциировано с карточкой желтого цвета, а желтый цвет был на 1-м месте, значит, само место может быть обозначено как наименее неприятное. Данный анализ не считается исчерпывающим или самостоятельным, но выступает интересным дополнением к основному анализу.

Данные прилагательные были выбраны в качестве обобщающих для наиболее часто упоминаемых ассоциаций с различными уровнями пространства (своей комнаты или квартиры, подъезда, двора, района и города) из предыдущего исследования автора. Ассоциации из категорий двора, района и города были проанализированы с помощью контент-анализа. Выбор обусловлен зоной покрытия - каждый ответ можно отнести к одной из этих категорий без привлечения дополнительных, что свидетельствует о построении модели, описывающей все пространство вариаций.

Каждому месту был присвоен ранг активности среды, где 1 - первая ступень, обозначающая минимальное количество активности в месте, т. е. минимальные скорость и темп проявления, и интенсивность любой деятельности находящихся в окружающем пространстве объектов, а 4-максимальные. Также 1-е, 2-е и 4-е места были отмечены большинством респондентов как знакомые (т. е. они бывали в этих местах как минимум один раз). Место «3. Дворик художеств», напротив, охарактеризовано в качестве незнакомого большинством (90\%) респондентов. Активность среды как собирательный образ движений различных объектов в окружающем пространстве оказывает наиболее сильное влияние на сенсорную систему человека и поэтому легче опознается человеком (Шилин, 2011).

Приведем характеристики среды, в рамках которой был проведен эксперимент.

Место «1. Пешеходная линия»- пешеходная улица, 6-я и 7-я линии В. О. в промежутке от Среднего до Большого проспекта. Характеризуется отсутствием машин (за некоторым исключением проезжающих служебных автомобилей, 3 случая из 31), максимальным количество людей, а также низким темпом ходьбы и присутствием уличных музыкантов, торговцев и агитаторов. В то же время данная улица большинством респондентов оценена в качестве уютной и домашней. Ранг 3 из 4-х по степени активности.

Место «2. Большой проспект»- Большой проспект В. О. в промежутке от пешеходной 6-й и 7-й линий до 2-й и 3-й линий В. О. Несмотря на тот факт, что эта улица является основной 
ПРОСКУРЯКОВА Е. А.

СУБЪЕКТИВНАЯ ОЦЕНКА МЕСТ ЖИТЕЛЯМИ САНКТ-ПЕТЕРБУРГА

Российский психологИчЕский жУРнАл, 2020, Т. 17, № 2, 36-57. doi: 10.21702/rpj.2020.2.3

ОБЩАЯ ПСИХОЛОГИЯ, ПСИХОЛОГИЯ ЛИЧНОСТИ, ИСТОРИЯ ПСИХОЛОГИИ

из магистралей, она представляется минимально активным местом. Количество людей в окружающем пространстве, как правило, было представлено меньше среднего, в том же диапазоне количество машин. Ранг 2.

Место «3. Дворик художеств»- парк во дворе Академии художеств. Место интересно тем, что является новым для большинства испытуемых, характеризуется тишиной, малым количеством людей, периодическим пребыванием лошадей (на территории находится конюшня) и собак. Ранг 1.

Место «4. Набережная» - часть набережной вдоль дворца Меншикова. Место отличается чрезвычайно расслабляющим видом справа (заснеженная р. Нева) и быстрым и шумным потоком машин слева. Ранг 4.

\section{Результаты}

Расчет происходил в программе SPSS Statistics 26-й версии методом непараметрических корреляций Спирмена, поскольку шкалы носят характер ранговых, а также с помощью факторного и регрессионного анализа.

Нам представляется важным обратить внимание на количество связей, получившихся в результате обработки, поскольку этот параметр показывает степень единения данных, их логичную связь (табл. 1). Самое большое их количество отмечено при сравнении оценок места «3. Дворик художеств» (первый наименьший ранг активности) между собой, а наименьшее количество в месте «4. Набережная» (наибольший четвертый ранг). Таким образом, количество значимых корреляций обратно выраженности ранга. Обоснованием этого вывода также может стать уточнение: третье место для преобладающего большинства опрошенных и большинства жителей города в генеральной совокупности считается незнакомым, и многие воспринимали его как новое. Место «4. Набережная» для петербургской публики выглядит максимально привычным, поскольку данное место представляет собой часть набережной р. Невы, пролегающей рядом с оживленной магистралью. Количество корреляций (а это очевидно) имеет значение, поскольку чем больше связей обнаружено в месте, тем более связные, неотрывочные сведения получены из этого места.

Большее количество связей с уровнем значимости $\mathrm{p}<0,01$ обнаружилось во втором и третьем местах с наименьшими рангами активности, что может говорить о получении более согласованных между собой данных из мест с меньшей активностью. Более того, если обратить внимание на разброс в процентном отношении, можно говорить о ранжировании в последовательности, обратной расположению рангов мест: чем меньше ранг места, тем в большем количестве проявилось соотношение количества более значимых корреляций к общему количеству значимых корреляций.

Связей с большей выраженностью параметра силы (при F > 0,5) в большем количестве было замечено в месте «3. Дворик художеств» и наименьшее в месте «4. Набережная», что аналогично первому выводу. Кроме того, разброс чисел наблюдается в обратной последовательности распределению рангов: чем выше ранг места (оно более активное), тем в меньшей степени наблюдаются корреляции с высоким уровнем $\mathrm{F}$.

Также во всех местах были отмечены связи следующих категорий: «угнетающее», «спокойное», «отталкивающее», «суетное», «безопасное», «уютное», «чистое», «культурное», «с ощущением новизны», «любимое», «престижное» и «комфортное». Наибольшее количество связей из них было у категорий «притягивающее», «отталкивающее», «спокойное», 
ПРОСКУРЯКОВА Е. А.

СУБЪЕКТИВНАЯ ОЦЕНКА МЕСТ ЖИТЕЛЯМИ САНКТ-ПЕТЕРБУРГА

РосСИЙСКИЙ пСИХОЛОГИЧЕСКИЙ ЖУРнАл, 2020, Т. 17, № 2, 36-57. doi: 10.21702/rpj.2020.2.3

ОБЩАЯ ПСИХОЛОГИЯ, ПСИХОЛОГИЯ ЛИЧНОСТИ, ИСТОРИЯ ПСИХОЛОГИИ

«угнетающее», «приятное», наименьшее - у «комфортное», «престижное», «с ощущением новизны».

\begin{tabular}{|c|c|c|c|c|c|c|c|}
\hline \multicolumn{8}{|c|}{$\begin{array}{l}\text { Таблица } 1 \\
\text { Сравнительный анализ значимых корреляций }\end{array}$} \\
\hline Место & $\underline{\mathrm{PaH} \Gamma}$ & $\frac{\text { КОА-вО }}{\text { Связей, шт. }}$ & $\begin{array}{l}\frac{\text { Кол-во }}{\text { Связей при }} \\
\underline{p<0,01,} \\
\text { Шт. }\end{array}$ & $\begin{array}{l}\text { Отношение } \\
\text { кол-ва связей } \\
\text { прир<0,01 } \\
\text { К общему кол- } \\
\text { ву,\% }\end{array}$ & $\begin{array}{l}\frac{\text { Кол-во }}{\text { Связей }} \\
\frac{\text { с наиб. F }}{(п р и F>} \\
\underline{0,5), \text { шт. }}\end{array}$ & $\begin{array}{l}\text { Отношение } \\
\text { Ко^-ва } \\
\text { Связей } \\
\text { с наиб. F } \\
\text { К общему } \\
\text { Кол-ву.\% }\end{array}$ & $\begin{array}{l}\text { Отношение } \\
\text { Связей } \\
\frac{\text { с наиб. F }}{\text { К связям при }} \\
\underline{\mathrm{p<0,01, \%}}\end{array}$ \\
\hline 1 & 3 & 58 & 34 & 58,62 & 28 & 48,28 & 82,35 \\
\hline 2 & 2 & 55 & 34 & 61,82 & 27 & 49,09 & 79,41 \\
\hline 3 & 1 & 89 & 63 & 70,79 & 46 & 51,69 & 73,02 \\
\hline 4 & 4 & 47 & 24 & 51,06 & 17 & 36,17 & 70,83 \\
\hline
\end{tabular}

Отдельно были выделены категории «притягивающее» и «отталкивающее» в качестве основных характеризующих отношение к месту. «Притягивающее» место (на основе значимых корреляций по всем местам) - это «комфортное», «любимое», «уютное» в 4-х местах, «безопасное», «спокойное» и «приятное» в 3-х местах, «престижное», «чистое», «с ощущением новизны» в 2-х местах, «культурное», не «угнетающее» и не «отталкивающее» в 1-м месте, а именно в месте «3. Дворик художеств». «Отталкивающее»- не «чистое», не «любимое» и «тревожное» в 4-х местах, не «уютное», не «культурное» и не «комфортное» в 3-х, не «престижное» и не «безопасное» в одном, а именно в месте «1. Пешеходная линия», а также «суетное» и не «притягивающее» в месте «3. Дворик художеств».

Также был проведен факторный анализ всех оценок мест отдельно в каждом месте, а затем регрессионный анализ полученных факторов. В качестве предикторов использовались все результаты стандартизированных психологических методик. Для удобства анализа оценки были разделены на 4 группы: положительные ощущения, характеристики среды, коллективные представления и отрицательные ощущения. Результаты продемонстрированы в таблицах 2-5. Данные распределены по местам. В начале ячеек указан скорректированный R квадрат. С каждой новой цифры - коэффициента уравнения - начинается новый предиктор. Отрицательные коэффициенты помечены знаком (-). Например, оценка «приятное» в 1-м месте объяснена на 34,4\%, затем предиктор с положительным коэффициентом 0,265 опросника МИС С. Р. Пантилеева в шкале «отраженное самоотношение», отрицательный коэффициент 0,020 опросника САМОАЛ «автономность» и положительный коэффициент 0,033 - данные с нейродевайса по шкале расслаблений. Повторяющиеся в рамках одной таблицы предикторы выделены полужирным. 
ПРоскУРЯкова Е. А.

СУБЪЕКТИВНАЯ ОЦЕНКА МЕСТ ЖИТЕЛЯМИ САНКТ-ПЕТЕРБУРГА

РОсСИЙСКИЙ ПСИХОЛОГИЧЕСКИЙ ЖУРНАЛ, 2020, Т. 17, № 2, 36-57. doi: 10.21702/rpj.2020.2.3

ОБЩАЯ ПСИХОЛОГИЯ, ПСИХОЛОГИЯ ЛИЧНОСТИ, ИСТОРИЯ ПСИХОЛОГИИ

Таблица 2
Результаты регрессионного анализа в группе «положительные ощущения»

Притяги-
вающее

1. Пеше-

холная 7-я Нет уравнения Нет уравнения Нет уравнения

Аиния В. О.

$\begin{array}{ll} & \text { Скорр. R кв. } \\ & 28,6 \% \\ \text { 2. Большой } & 0,260 * \text { м2 } \\ \text { проспект } & \text { опосре- } \\ \text { В. О. } & \text { Аованный цвет } \\ & +0,031 \text { * } \\ & \text { торможение } \\ & \text { СТР }\end{array}$

CTP

Скорр. R кв.
$28,6 \%$
$0,260 *$ м2
опосре-
Аованный цвет
$+0,031^{*}$ тормо-
жение Стр

Скорр. R кв.

$28,6 \%$

$0,260 * M 2$

опосре-

Аованный цвет

$+0,031 *$

торможение

CTP
Cкорр. R кв.

$34,4 \%$

0,265* MИС

отраженное

самоотношение

(-) 0,020 *

CAMOA^

автонОМность

$0,033 * 1 M$

расслабление

Нет уравнения

Cкорр. R кв.

$28,6 \%$

$0,260 * M 2$

опосре-

Аованный цвет

+ 0,031 * тормо-

жение СТP
Cкорр. R кв.

$28,6 \%$

$0,260 * M 2$

опосре-

Аованный цвет

+ 0,031 * тормо-

жение СТP

\begin{tabular}{|c|c|c|c|c|c|}
\hline & Скорр. R кв. & $\mathrm{He}$ & Скорр. R кв. & Скорр. R кв. & Скорр. R кв. \\
\hline & $14,1 \%$ & Скорр. R кв. & $18,2 \%$ & $14,1 \%$ & $14,1 \%$ \\
\hline 3. Аворик & $0,244 * M 3$ & $48,4 \%$ & $(-) 0,097^{*}$ & $0,244 *$ M3 & $0,244 *$ M3 \\
\hline художеств & OпосреАо- & (-) 0,038 *\% & суверенность & опосре- & опосре- \\
\hline & ВанныИ цвет & экстраверсии & фризического & АОваннЫИ цвет & \\
\hline & & $0,311 * M И C$ & те^a & & \\
\hline & & открытость & & & \\
\hline
\end{tabular}


ПРОСКУРЯКОВА Е. А.

СУБЪЕКТИВНАЯ ОЦЕНКА МЕСТ ЖИТЕЛЯМИ САНКТ-ПЕТЕРБУРГА

РОССИЙСКИЙ ПСИХОЛОГИЧЕСКИЙ ЖХРНАл, 2020, Т. 17, № 2, 36-57. doi: 10.21702/rpj.2020.2.3

ОБЩАЯ ПСИХОЛОГИЯ, ПСИХОЛОГИЯ ЛИЧНОСТИ, ИСТОРИЯ ПСИХОЛОГИИ

\section{Таблица 2 \\ Результаты регрессионного анализа в группе «положительные ощущения»}

\begin{tabular}{|c|c|c|c|c|c|}
\hline & $\begin{array}{l}\text { Притяги- } \\
\text { вающее }\end{array}$ & Комдрортное & $\underline{\text { Уютное }}$ & Приятное & Спокойное \\
\hline $\begin{array}{l}\text { 4. Набе- } \\
\text { режная } \\
\text { напротив } \\
\text { Аворца Мен- } \\
\text { шикова }\end{array}$ & $\begin{array}{l}\text { Скорр. R кв. } \\
30,3 \% \\
(-) \text { 0,032* } \\
\text { УАОвлет- } \\
\text { воренность } \\
\text { жизнью } \\
\text { 0,019 * САМОА^ } \\
\text { прироАа } \\
\text { человека }\end{array}$ & Нет уравнения & $\begin{array}{l}\text { Скорр. R кв. } \\
\text { 30,3\% } \\
\text { (-) 0,032 * } \\
\text { УАОв^ет- } \\
\text { воренность } \\
\text { жизнью } \\
\text { 0,019 * } \\
\text { САМОА^ } \\
\text { прироАа } \\
\text { человека }\end{array}$ & $\begin{array}{l}\text { Скорр. R кв. } \\
\text { 30,3\% } \\
(-) \text { 0,032 * } \\
\text { УАОв^ет- } \\
\text { воренность } \\
\text { жизнью } \\
\text { 0,019 * САМОАА } \\
\text { прироАа } \\
\text { человека }\end{array}$ & Нет уравнения \\
\hline
\end{tabular}

Таблица 3

Результаты регрессионного анализа в группе «характеристики среды»

$\underline{\text { Чистое }} \underline{\text { Просторное }} \underline{\text { Активное }} \underline{\text { Новизна }}$

1. Пеше-

хоАная 7-я

Аиния В. О.
Скорр. R кв.

$17,7 \%$

(-) $0,106 *$

суверенность

территории
Cкорр. R кв.

$17,7 \%$

(-) 0,106 *

суверенность

территории
Cкорр. R кв.

$30,2 \%$

(-) 0,027 *

CAMOA^

аутосимпатия

0,092 * суверен-

ность терри-

тории
Скорр. R кв.

$32,6 \%$

(-) $0,217 * \mathrm{MUC}$ внутренняя

Нет уравнения КОНОА ИКТНОСТЬ $+0,042 * 1 \mathrm{M}$ возбужление 
ПРоскУРЯкова Е. А.

СУБЪЕКТИВНАЯ ОЦЕНКА МЕСТ ЖИТЕЛЯМИ САНКТ-ПЕТЕРБУРГА

РОсСиЙСКИЙ пСИХОЛОГИЧЕСКИЙ ЖУРНАЛ, 2020, Т. 17, № 2, 36-57. doi: 10.21702/rpj.2020.2.3

ОБЩАЯ ПСИХОЛОГИЯ, ПСИХОЛОГИЯ ЛИЧНОСТИ, ИСТОРИЯ ПСИХОЛОГИИ

\begin{tabular}{|c|c|c|c|c|c|}
\hline & 4истое & Просторное & Активное & Новизна & $\underline{\text { Светлое }}$ \\
\hline $\begin{array}{l}\text { 2. Большой } \\
\text { проспект } \\
\text { В. О. }\end{array}$ & $\begin{array}{l}\text { Скорр. R кв. } \\
44,5 \% \\
\text { (-) 0,332 * МИС } \\
\text { отраженное } \\
\text { самоотношение } \\
0,060 * 2 \mathrm{M} \\
\text { возбуждение }\end{array}$ & $\begin{array}{l}\text { Скорр. R кв. } \\
44,5 \% \\
(-) \text { 0,332 } \\
\text { * МИС } \\
\text { отраженное } \\
\text { само- } \\
\text { отношение } \\
\text { 0,060 * 2м } \\
\text { возбуждение }\end{array}$ & $\begin{array}{l}\text { Скорр. R кв. } \\
\text { 69,8\% } \\
\text { 0,522 * МИС } \\
\text { открытость } \\
\text { (-) 0,030 * } \\
\text { САМОА^ время } \\
\text { 0,033 САМОАА } \\
\text { ценности } \\
\text { (-) 0,203 * МИС } \\
\text { саморуко- } \\
\text { воАство } \\
\text { (-) 0,064 * } \\
\text { суверен. } \\
\text { привычек } \\
\text { 0,050 * суверен. } \\
\text { вещей }\end{array}$ & $\begin{array}{l}\text { Скорр. R кв. } \\
\text { 69,8\% } \\
\text { 0,522 * МИС } \\
\text { открытость } \\
\text { (-) 0,030 * } \\
\text { САМОАА } \\
\text { время } \\
\text { 0,033 САМОАА } \\
\text { ценности } \\
\text { (-) 0,203 * МИС } \\
\text { саморуко- } \\
\text { воАство } \\
\text { (-) 0,064 * } \\
\text { суверен. } \\
\text { привычек } \\
\text { 0,050 * } \\
\text { суверен. } \\
\text { вещей }\end{array}$ & $\begin{array}{l}\text { Скорр. R кв. } \\
44,5 \% \\
\text { (-) 0,332 * } \\
\text { миС отра- } \\
\text { женное само- } \\
\text { отношение } \\
\text { 0,060 * 2м } \\
\text { возбуждение }\end{array}$ \\
\hline $\begin{array}{l}\text { 3. Аворик } \\
\text { художеств }\end{array}$ & $\begin{array}{l}\text { Hе } \\
\text { Скорр. R кв. } \\
27,3 \% \\
0,111 * \text { суверен- } \\
\text { ность соц. } \\
\text { связей } \\
\text { (-) 0,045 * 3м } \\
\text { расслабление }\end{array}$ & $\begin{array}{l}\text { Скорр. R кв. } \\
14,1 \% \\
0,244 * \text { м3 } \\
\text { опосреАо- } \\
\text { ванный цвет }\end{array}$ & $\begin{array}{l}\text { Скорр. R кв. } \\
27,3 \% \\
0,111 * \text { суверен- } \\
\text { ность соц. } \\
\text { связей } \\
\text { (-) 0,045*3м } \\
\text { расслабление }\end{array}$ & $\begin{array}{l}\text { Скорр. R кв. } \\
14,1 \% \\
0,244 \text { * м3 } \\
\text { опосреАо- } \\
\text { ванный цвет }\end{array}$ & $\begin{array}{l}\text { Скорр. R кв. } \\
40,2 \% \\
=-0,144 \\
(\text { незн) + 0,396 } \\
{ }^{*} \text { м3 опосре- } \\
\text { Аованный цвет } \\
\text { - 1,910* уст R } \\
\text { СТР }\end{array}$ \\
\hline $\begin{array}{l}\text { 4. Набереж- } \\
\text { ная }\end{array}$ & Нет уравнения & Нет уравнения & Нет уравнения & Нет уравнения & Нет уравнения \\
\hline
\end{tabular}


ПРОСКУРЯКОВА Е. А.

СУБЪЕКТИВНАЯ ОЦЕНКА МЕСТ ЖИТЕЛЯМИ САНКТ-ПЕТЕРБУРГА

РОССИЙСКИЙ ПСИХОЛОГИЧЕСКИЙ ЖУРНАЛ, 2020, Т. 17, № 2, 36-57. doi: 10.21702/rpj.2020.2.3

ОБЩАЯ ПСИХОЛОГИЯ, ПСИХОЛОГИЯ ЛИЧНОСТИ, ИСТОРИЯ ПСИХОЛОГИИ

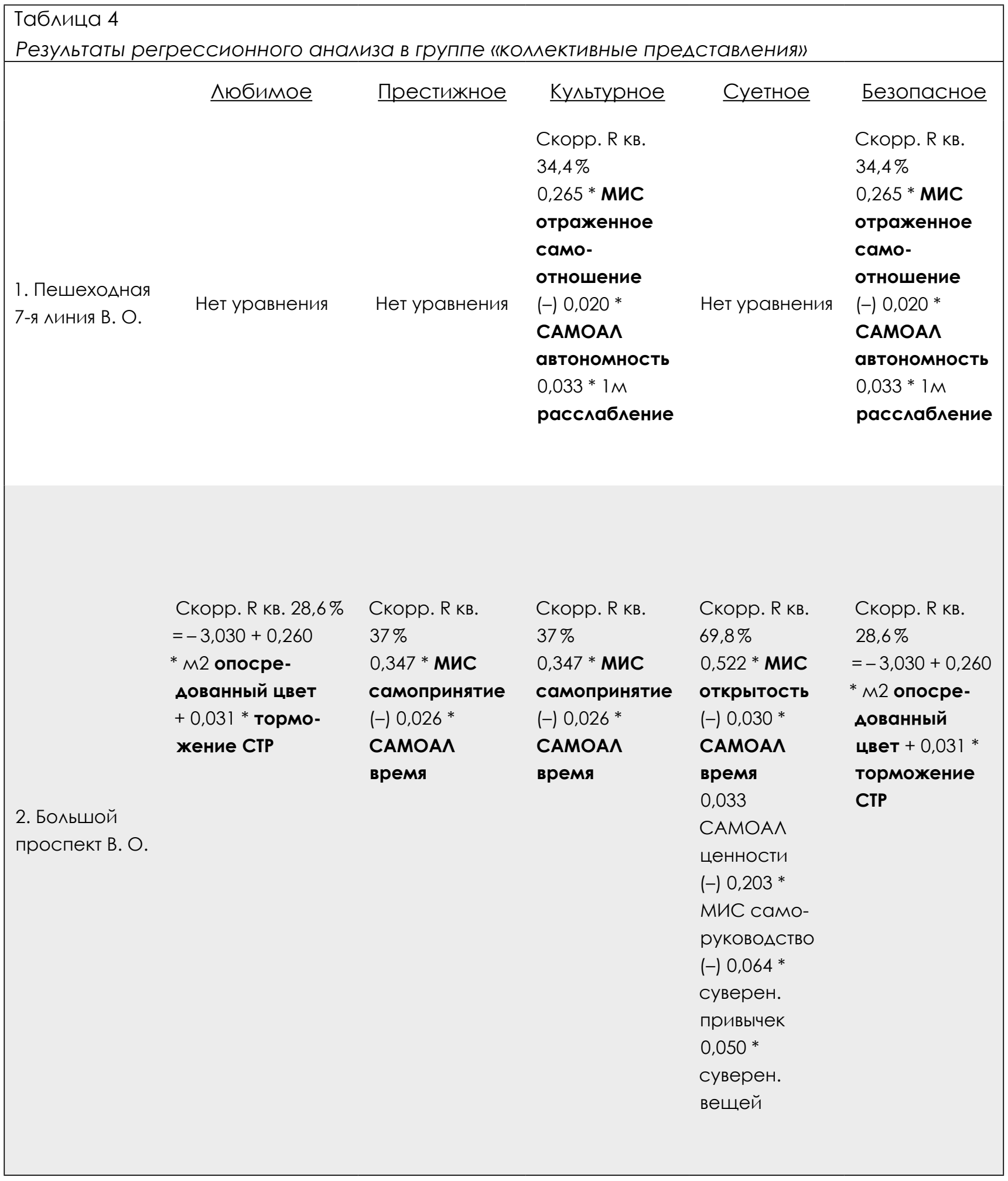


ПРоскУРЯкова Е. А.

СУБЪЕКТИВНАЯ ОЦЕНКА МЕСТ ЖИТЕЛЯМИ САНКТ-ПЕТЕРБУРГА

РОсСиЙСКИЙ пСИХОЛОГИЧЕСКИЙ ЖУРНАЛ, 2020, Т. 17, № 2, 36-57. doi: 10.21702/rpj.2020.2.3

ОБЩАЯ ПСИХОЛОГИЯ, ПСИХОЛОГИЯ ЛИЧНОСТИ, ИСТОРИЯ ПСИХОЛОГИИ

\begin{tabular}{|c|c|c|c|c|c|}
\hline $\begin{array}{l}\text { 3. Аворик } \\
\text { Художеств }\end{array}$ & $\begin{array}{l}\text { Не } \\
\text { Скорр. R кв. 48,4\% } \\
=-0,008 \text { (незнач) } \\
\text { - 0,038 *\% экстра- } \\
\text { версии } \\
+0,311 * \text { мис } \\
\text { открытость }\end{array}$ & $\begin{array}{l}\text { Скорр. R кв. } \\
\text { 18,2\% } \\
=0,443 \\
\text { (незн) - 0,097 * } \\
\text { суверенность } \\
\text { физического } \\
\text { тела }\end{array}$ & $\begin{array}{l}\text { Скорр. R кв. } \\
14,1 \% \\
0,244 \text { * м3 } \\
\text { опосре- } \\
\text { Аованный цвет }\end{array}$ & $\begin{array}{l}\text { Скорр. R кв. } \\
27,3 \% \\
0,111 * \\
\text { суверенность } \\
\text { соц. связей } \\
\text { (-) 0,045 *3м } \\
\text { расслаб- } \\
\text { ление }\end{array}$ & $\begin{array}{l}\text { Скорр. R кв. } \\
40,2 \% \\
0,396 \text { * м3 } \\
\text { опосре- } \\
\text { Аованный } \\
\text { цвет } \\
(-) 1,910 * \text { Уст } \\
\text { R СТP }\end{array}$ \\
\hline 4. Набережная & $\begin{array}{l}\text { Скорр. R кв. 30,3\% } \\
\text { (-) 0,032 * уАов^ет- } \\
\text { воренность } \\
\text { жизнью } \\
0,019 * \text { САМОА^ } \\
\text { прирола } \\
\text { человека }\end{array}$ & Нет уравнения & Нет уравнения & Нет уравнения & Нет уравнения \\
\hline
\end{tabular}

Таблица 5

Результаты регрессионного анализа в группе «отрицательные ощущения»

$\underline{\text { Угнетающее }}$

Тревожное

Отталкивающее

Скорр. R кв. 34,4\%

$\mathrm{He}$

0,265 * мИС отраженное

1. Пешеходная 7-я Аиния В. О.
(-) 0,020 * CAMOA^

автонОМность

$0,033 * 1$ м расслабление
Скорр. R кв. 34,4\%

$\mathrm{He}$

$0,265 *$ миС отраженное самоотношение

(-) 0,020 * CAMOAA автонОМность

$0,033 * 1$ м расслабление
Cкорр. R кв. 34,4\%

$\mathrm{He}$

0,265 * МИС отраженное самоотношение

(-) 0,020 * CAMOA^ автонОМность $0,033 * 1$ м расслабление 
ПРОСКУРЯКОВА Е. А.

СУБЪЕКТИВНАЯ ОЦЕНКА МЕСТ ЖИТЕЛЯМИ САНКТ-ПЕТЕРБУРГА

РОССИЙСКИЙ ПСИХОЛОГИЧЕСКИЙ ЖУРНАЛ, 2020, Т. 17, № 2, 36-57. doi: 10.21702/rpj.2020.2.3

ОБЩАЯ ПСИХОЛОГИЯ, ПСИХОЛОГИЯ ЛИЧНОСТИ, ИСТОРИЯ ПСИХОЛОГИИ

Таблица 5
Результаты регрессионного анализа в группе «отрицательные ощущения»

Скорр. R кв. 70,2\%

Скорр. R кв. 70,2\%

Скорр. R кв. 70,2\%

(-) 0,046* CAMOA^

(-) 0,046* CAMOAА

(-) $0,046 *$ CAMOA^

прироАа человека

прироАа человека

прироАа человека

0,026 * УАОвлет-

воренность жизнью

0,026 * УАовлет-

воренность Жизнью

0,026 * УАОвлет-

воренность жизнью

$0,048 *$ CAMOA^

$0,048 *$ CAMOAA

креативность

2. Большой креативность

$0,219 *$ МИС внутренняя

конфАиктность

креативность

$0,219 *$ МИС внутренняя

конфАиктность

0,061 * суверенность

физического тела

физического тела

0,157 * МИС

самопринятие
0,219* МИС внутренняя

конфАиктность

0,061 * суверенность

физического тела

$0,157 *$ МИС

самопринятие
3. $\triangle в о р и к ~$
$\mathrm{He}$
хуАОжеств
Cкорр. R кв. 48,4\%
$\mathrm{He}$
(-) 0,038 *\% экстраверсии
Скорр. R кв. 48,4\%
$\mathrm{He}$
$+0,311 *$ МИС открытость
(-) 0,038 *\% экстраверсии
Cкорр. R кв. 48,4\%
$+0,311 *$ МИС открытость
(-) 0,038 *\% экстраверсии
$+0,311 *$ МИС открытость
Cкорр. R кв. 29,4\%
4. Набережная
(-) $0,039 * 4 \mathrm{M}$
расслабление
Нет уравнения
0,024 * \% экстраверсии
Cкорр. R кв. 29,4\%
(-) $0,039 * 4 \mathrm{M}$
расслабление
0,024 * \% экстраверсии 
ПРОСКУРЯКОВА Е. А.

СУБЪЕКТИВНАЯ ОЦЕНКА МЕСТ ЖИТЕЛЯМИ САНКТ-ПЕТЕРБУРГА

Российский психологИчЕский жУРнАл, 2020, Т. 17, № 2, 36-57. doi: 10.21702/rpj.2020.2.3

ОБЩАЯ ПСИХОЛОГИЯ, ПСИхОЛОГИЯ лИЧнОстИ, ИСТОРИя ПСИхОЛОГИИ

\section{Выводы по регрессионному анализу}

Большинство негативных характеристик участвуют в фактором анализе «перевернутые», с минусом, т.е. в положительном смысле. Похожее распределение оценок в факторы от места к месту. Отличия: отдельно выделялись «ощущение новизны» и «культурное».

В первом факторе у трех мест, кроме места «3. Дворик художеств», произошло объединение трех оценок: «притягивающее», «любимое», «уютное», а в двух первых местах - даже объединение четырех оценок: «притягивающее», «комфортное», «уютное», «любимое». Вывод (подтверждает корреляционный): притягивающее место чаще всего «уютное», а также может совпадать с «любимым».

Оценки «престижное» и «культурное» планировалось использовать как маркер коллективного представления. В одном факторе они встречаются дважды-в третьем и четвертом месте. В каждом месте он связан с различными оценками. Основной вывод: категории, которые каким-либо образом можно было бы отнести к оценкам, в большей степени основанным на коллективных представлениях, группируются не между собой, отдельно от других представлений или ощущений, а вместе с ними, что показывает связь коллективных представлений с ощущениями.

«Просторное» и «чистое»- связь в первых двух местах. Затем «просторное» вместе с «комфортным», «культурным», «престижным», «светлым» в четвертом месте и с «культурным», «притягивающим», «спокойным», «приятным» и «ощущением новизны» в третьем месте. В новом месте в первый фактор с категорией «притягивающее» попадает «ощущение новизны», и этот фактор обуславливается только предиктором опосредованного цвета.

«Угнетающее», «тревожное», «отталкивающее» в трех местах втроем, а в четвертом месте «тревожное» объединилось с «ощущением новизны».

Испытуемые надевали в самом начале нейродевайс, считывающий импульсы мозга и отмечающий в приложении каждую минимальную единицу времени размер возбуждения и расслабления на данный момент. Результат: расслабление отрицательно связано с угнетением - в трех местах показано, что показатель расслабленности мозга связан с оценкой «угнетающее», а также другими отрицательными («суетное», «нечистое», «отталкивающее»).

\section{Выводы по группам оценок}

В группе «приятные самоощущения» («притягивающее», «комфортное», «уютное», «приятное», «спокойное») самое большое численное выражение у предикторов МИС в шкалах «отраженное самоотношение» и «открытость». Чем выше показатели по шкале «отраженное самоотношение», тем более приятным является место. Чем больше «открытость», тем меньше оценка комфорта. В той же логике суверенность психологического пространства минимально выражена через шкалу «суверенность физического тела» только в одном, третьем, месте: чем выше выражена суверенность тела, тем менее уютным оценивается место. Опосредованный цвет выступает предиктором всех четырех оценок в категории «приятные ощущения» во втором месте и у двух оценок в третьем месте, что показывает важность значения неосознаваемых ощущений в этой группе оценок.

В этой группе также наблюдается среднее влияние темперамента - торможение по методике Я. Стреляу во втором месте, расслабление в первом и экстраверсия в третьем. Удовлетворенность жизнью влияет на оценки противоположным образом: чем ниже удовлетворенность, тем выше будет положительная оценка. Видно минимальное влияние шкалы САМОАЛ «природа 
ПРОСКУРЯКОВА Е. А.

СУБЪЕКТИВНАЯ ОЦЕНКА МЕСТ ЖИТЕЛЯМИ САНКТ-ПЕТЕРБУРГА

РосСИЙСКИЙ пСИХОЛОГИЧЕСКИЙ ЖУРнАл, 2020, Т. 17, № 2, 36-57. doi: 10.21702/rpj.2020.2.3

ОБЩАЯ ПСИХОЛОГИЯ, ПСИХОЛОГИЯ ЛИЧНОСТИ, ИСТОРИЯ ПСИХОЛОГИИ

человека», которая подразумевает веру в могущество человеческих возможностей: чем сильнее вера в человечество, тем выше оценки из категории «приятное» (на примере 4-го места «Набережная»). Еще одна шкала САМОАЛ «автономность»: чем выше показатель по данной шкале, тем меньше выражена оценка «приятное» (на примере 1-го места «Пешеходная линия»).

В группе оценок «характеристики среды» («чистое», «просторное», «активное», «новизна», «светлое») в четвертом месте не произвелись уравнения-подразумевается, что полученные оценки обусловлены в большей степени чем-то еще. В большом объеме представлены связи со шкалами из опросника «Суверенность психологического пространства»: суверенность территории обуславливает чистоту, простор и активность среды первого места, суверенность привычек и вещей влияет на оценку активности и новизны среды, суверенность социальных связей - на чистоту и активность в третьем месте.

В группе «коллективные представления» («любимое», «престижное», «культурное», «суетное», «безопасное») суверенность физического тела влияет на оценку престижности третьего места, а суверенность привычек и вещей влияет на оценку суетности второго места, и суверенность социальных связей - на оценку суетности в третьем месте. Опросник МИС представлен также шкалами «саморуководство», «отраженное самоотношение» (одна из наиболее часто представленных шкал в качестве предиктора), «самопринятие» и «открытость». Из опросника САМОАЛ в виде предикторов выделились «автономность», «время», «ценности» и «природа человека» - шкалы, говорящие об общих представлениях человека: о ценности жизни, распределении времени, о согласии с набором ценностей самоактуализирующегося человека, что совпадает со смыслом группы и частично подтверждает предположение автора. Темперамент: экстраверсия связана с «любимое», а также есть четыре связи с возбуждением, две - с торможением и шкалой Стреляу.

Группа «отрицательные ощущения» («угнетающее», «тревожное», «отталкивающее») показывает большую насыщенность предикторами, только одно уравнение пропущено. Все оценки связаны с суверенностью физического тела во втором месте. Темперамент: в третьем и четвертом месте наблюдается 5 связей из 6 с экстраверсией, в четвертом месте наблюдается отрицательная связь с расслабленностью, есть связь со шкалами Стреляу. Кроме того, на отрицательные оценки большое влияние оказывают «отраженное самоотношение», «внутренняя конфликтность», «самопринятие» и «открытость» из опросника МИС. Из опросника самоактуализации в качестве предикторов в группе представлены «креативность», «природа человека» и «автономность».

В итоге суверенность психологического пространства в большей степени обуславливает оценки, описывающие характеристики среды: «чистое», «просторное», «активное», «новизна», а также «суетное» из категории представлений. Показатель расслабленности связан с положительным ощущением места. Шкалы МИС «отраженное самоотношение», «внутренняя конфликтность», «саморуководство», «самопринятие» и «открытость» условно равномерно представлены во всех группах оценок, без характерных всплесков в группах ощущений, что говорит о влиянии самоощущения на все оценки места. Из опросника самоактуализации активно представлены шкалы «природа человека», «время» и «аутосимпатия» во всех группах оценок. Также была замечена широкая представленность предиктора расслабленности во всех группах оценок. 
ПРОСКУРЯКОВА Е. А.

СУБЪЕКТИВНАЯ ОЦЕНКА МЕСТ ЖИТЕЛЯМИ САНКТ-ПЕТЕРБУРГА

РОССИЙСКИЙ ПСИХОЛОГИЧЕСКИЙ ЖУРнАЛ, 2020, Т. 17, № 2, 36-57. doi: 10.21702/rpj.2020.2.3

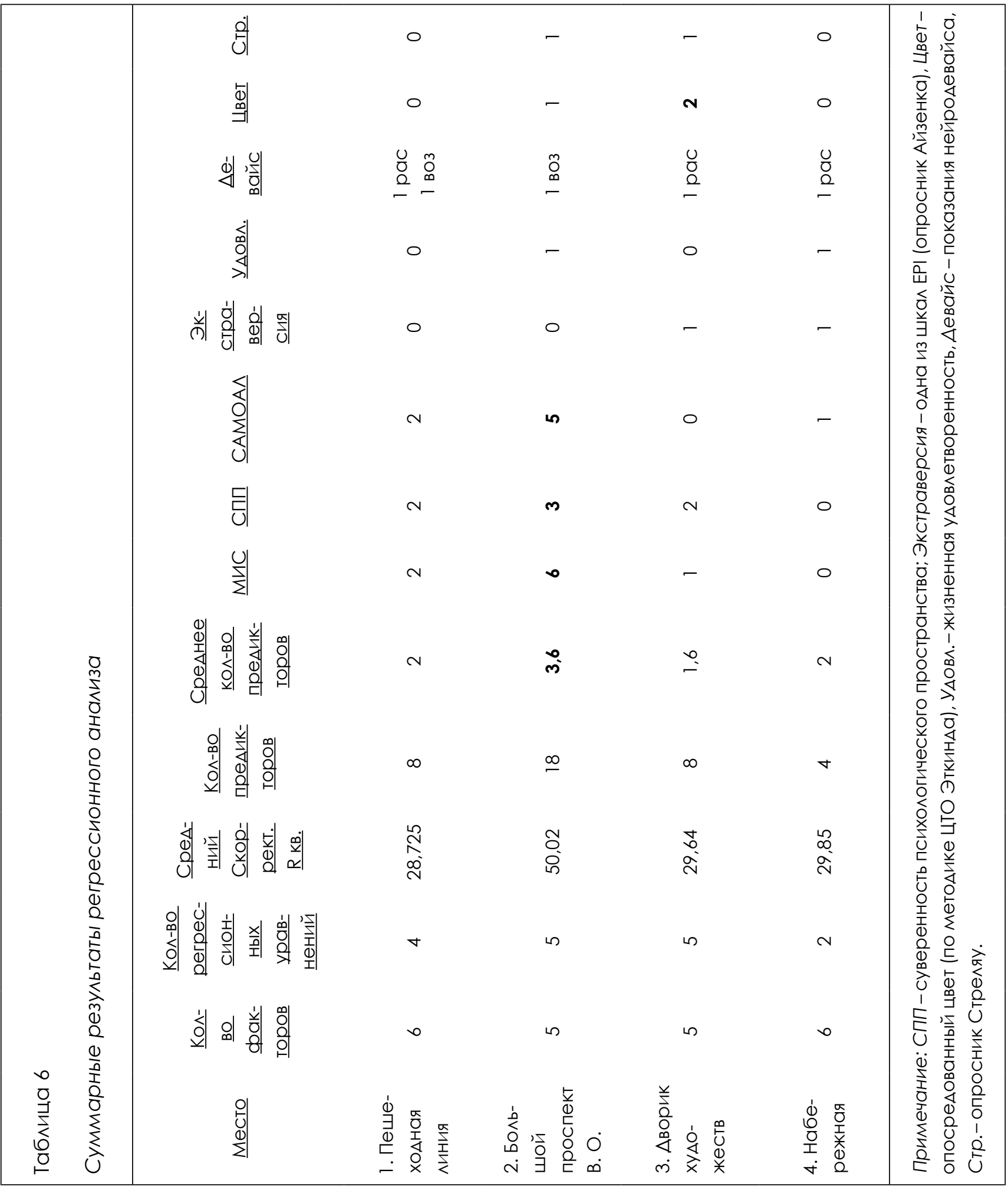


ПРОСКУРЯКОВА Е. А.

СУБЪЕКТИВНАЯ ОЦЕНКА МЕСТ ЖИТЕЛЯМИ САНКТ-ПЕТЕРБУРГА

РосСИЙСКИЙ пСИХОЛОГИЧЕСКИЙ ЖУРнАл, 2020, Т. 17, № 2, 36-57. doi: 10.21702/rpj.2020.2.3

ОБЩАЯ ПСИХОЛОГИЯ, ПСИХОЛОГИЯ ЛИЧНОСТИ, ИСТОРИЯ ПСИХОЛОГИИ

\section{Обсуждение результатов}

Можно говорить о том, что в незнакомых местах обнаруживается большее количество корреляций между оценками, поскольку проявляется большая мотивация в познавательной активности, мозг более активно изучает пространство и, соответственно, определяет, оценивает его. В наиболее привычных пространствах активность по восприятию места минимальна, и оценка места может складываться из уже имеющихся представлений о подобных местах, поэтому отдельные параметры оценки места могут не согласовываться с ощущениями в этом месте в настоящий момент, что противоречит той тенденции максимальной осознанности своих ощущений, о которой говорилось вначале. Возможно, человеку легче осознавать свои ощущения в местах с меньшим рангом активности мест - в наименее активных местах мы получаем от среды большее количество информации.

Удивительным стал факт, что категория «приятное», представляющаяся основной характеристикой места и располагающаяся первой в списке, получила связи не во всех местах, что не совпадает с дополнительной гипотезой. Совпал с опытом факт получения наименьшего количества связей у категории «с ощущением новизны», поскольку маршрут был выбран узнаваемый.

Получены уравнения «притягивающего» и «отталкивающего» мест: притягивающее место - это, прежде всего, комфортное и уютное место, если оно незнакомое или любимое, а отталкивающее место - нечистое, нелюбимое и тревожное. Получается, что необязательно месту быть престижным, новым и культурным, чтобы оно привлекало, но обязательно быть чистым и не вызывающим тревожность. С другой стороны, месту желательно быть культурным и комфортным, чтобы не отпугивало, т. е. именно в отрицательном контексте есть привязка к категориям, относящимся к стереотипным или коллективным образам, которые были увидены исследователем в предыдущей работе (Проскурякова, 2016; Проскурякова и Яничева, 2016).

В месте «4. Набережная» получились наименее предсказываемые данные: можно предположить, что в привычном месте в большей степени задействованы коллективные представления, поэтому результаты стандартизированных опросников в меньшей степени их объясняют - они ближе к индивидуальным ощущениям и представлениям отдельной личности.

Есть связи и с данными нейродевайса, и с экстраверсией, и с опосредованной музыкой, что подтверждает связи с темпераментом и неосознаваемыми процессами, хотя и в минимальном выражении коэффициента. В трех местах задействовано расслабление, в двух-возбуждение. Проявление опосредованного цвета в месте «3. Дворик художеств» самое большое - дополнительный аргумент в пользу проявления неосознанных ощущений.

Нет связей с нейротизмом, что противоречит изначальному предположению о связи с оценкой «тревожное» и другими негативными ощущениями, поэтому данное обстоятельство требует дополнительной проверки. Возможно, связь с оценкой «тревожное» покажет субъективная оценка уровня нейротизма личности.

С другой стороны, получено множество связей отрицательных оценок и параметра расслабления с нейродевайса, что может говорить о важности расслабления как условии отсутствия негативных оценок и, возможно, негативных ощущений в месте.

B трех местах примерно одинаковый средний скорректированный R квадрат, и только в одном втором месте, на Большом проспекте, он почти в два раза больше - данные, образовавшие факторы в этом месте, в гораздо большей степени обусловлены другим собранным набором данных, а в месте «З. Дворик художеств» самая низкая обусловленность 
ПРОСКУРЯКОВА Е. А.

СУБЪЕКТИВНАЯ ОЦЕНКА МЕСТ ЖИТЕЛЯМИ САНКТ-ПЕТЕРБУРГА

Российский психологИчЕский жУРнАл, 2020, Т. 17, № 2, 36-57. doi: 10.21702/rpj.2020.2.3

ОБЩАЯ ПСИХОЛОГИЯ, ПСИХОЛОГИЯ ЛИЧНОСТИ, ИСТОРИЯ ПСИХОЛОГИИ

предикторами. Данное обстоятельство требует проведения дополнительных процедур для выяснения возможных причин.

Показатель удовлетворенности жизни выступает предиктором отрицательных оценок во втором месте и предиктором в обратном случае с положительными оценками - в четвертом месте. Причем оценка, что дублируется в обоих случаях - «отталкивающее» и «притягивающее». Поэтому можно предположить, что показатель удовлетворенности жизни влияет на оценку притягивания места.

Итог эмпирического исследования - основная и дополнительная гипотезы подтвердились частично. Действительно, оценка места связана с параметрами активности среды и субъективной степени новизны. Оказалось, что новые места человек оценивает полнее, в большей степени опираясь на актуальные ощущения; привычные места оценены более скудно, что позволяет предположить основанность их оценки на коллективных представлениях. Из предполагаемых факторов - предикторов - подтвердился частично темперамент (экстраверсия есть, нейротизма нет). Аутосимпатия (ее эквивалент в виде баллов по одноименной шкале САМОАЛ) проявила себя только в качестве предиктора оценки «активное» в первом месте, но многие шкалы опросника МИС («отраженное самоотношение», «внутренняя конфликтность», «саморуководство», «самопринятие» и «открытость»), демонстрирующие самоощущение, проявили себя в качестве предикторов, причем с наибольшим коэффициентом, что подтверждает гипотезу. Также в рамках вопроса о личностных свойствах проверялась связь с суверенностью психологического пространства, уровнем самоактуализации личности и жизненной удовлетворенностью, которая также нашла выражение в качестве предикторов в уравнениях, представленных выше. «Приятное» не является синтезирующей категорией, поскольку она представлена в анализе не во всех местах, хотя и частично показывает общее отношение к месту. Вместо нее синтезирующими признаются категории «притягивающее» и «отталкивающее».

Таким образом, оценки мест связаны и зависят от самоощущения воспринимающего и его темперамента, а также от суверенности психологического пространства, уровня жизненной удовлетворенности и уровня самоактуализации личности, что показывает большую связь с его ощущениями и неким минимальным уровнем индивидуальных представлений. Большая часть необоснованности оценки места, возможно, зависит от коллективных представлений и других параметров.

В настоящий момент существует и транслируется потребность в трансформации своей личности, восстановлении ее «до целого» в рамках процесса самоактуализации. И в этом может помочь осознанное восприятие своих актуальных ощущений в новых местах с наименьшей активностью. С другой стороны, невозможность попадания в ситуацию неоценивания и невосприятия того, что находится вокруг человека, вероятно, создает механизмы, позволяющие максимально быстро сформировать мнение относительно близлежащих объектов с множеством параметров. Именно поэтому в ситуации, максимально похожей на часто повторяющуюся, как в случае с набережными в г. Санкт-Петербурге, человек автоматически будет относиться к этой набережной так же, как к большинству предыдущих, чтобы не тратить ресурс на более точное восприятие и оценку. Вполне закономерно, что данный механизм напоминает механизм формирования стереотипа и подтвердился в ходе эксперимента с самым повторяющимся местом у людей, совершающих пешие прогулки по центру г. Санкт-Петербурга и живущих в нем продолжительное время. Мы приходим к выводу, что каждый человек, зная, как протекает процесс, может приложить усилия к нахождению баланса. 
ПРОСКУРЯКОВА Е. А.

СУБЪЕКТИВНАЯ ОЦЕНКА МЕСТ ЖИТЕЛЯМИ САНКТ-ПЕТЕРБУРГА

РосСИЙСКИЙ пСИХОЛОГИЧЕСКИЙ ЖУРнАл, 2020, Т. 17, № 2, 36-57. doi: 10.21702/rpj.2020.2.3

ОБЩАЯ ПСИХОЛОГИЯ, ПСИХОЛОГИЯ ЛИЧНОСТИ, ИСТОРИЯ ПСИХОЛОГИИ

Кроме того, вопрос оценки пространства может быть связан с толерантностью к неопределенности - понятием, описанным в двух различных по подходу монографиях Т. В. Корниловой и Д. А. Леонтьева (Корнилова, Чумакова, Корнилов и Новикова, 2010; Леонтьев, Осин и Луковицкая, 2016). Например, новые пространства непредсказуемы и могут быть как опасными, так и неожиданно интересными. Данный факт подтверждает максимально большое количество корреляций и согласованных данных по месту «3. Дворик художеств»- незнакомому месту для большего числа опрашиваемых (более $90 \%$ ).

«Суждения Брунера и результаты экспериментов позволили сделать вывод о том, что при принятии перцептивного решения резко повышается вклад субъекта восприятия: он постоянно дает оценку воспринимаемому, а это уже всегда связано с различными социальными факторами, с конкретными жизненными обстоятельствами» (Андреева, 2000, с. 37). Тем самым хочется показать активную роль субъекта и сказать о том, что в силах человека частично влиять на протекание перцептивного процесса: экономить ресурс и рассматривать привычное пространство в рамках известных категорий. Этот механизм работает без усилий с человеческой стороны, но человек может осознанно находить менее активные места с ощущением новизны и познавать их, и пробовать осознавать актуальные ощущения, конструируя свой новый мир и себя.

\section{Литература}

Андреева, Г. М. (2000). Психология социального познания. Москва: Аспект Пресс.

Габидулина, С. Э. (2012). Психология городской среды. Москва: Смысл.

Дмитриева, Н. С. (2013). Модель жизненного пространства у подростков: предпосылки и направления исследования. Актуальные проблемы психологического знания, 3 (28), 90-98.

Дробышева, Т. В. и Журавлев, А. Л. (ред.) (2016). Сочиально-психологические исследования города. Москва: Институт психологии РАН.

Елисеев, О. П. (2000). Практикум по психологии личности. Санкт-Петербург: Питер.

Журавлев, А. Л. и Купрейченко, А. Б. (2012). Сочиально-психологическое пространство личности. Москва: Институт психологии РАН.

Знаков, В. В. (2016). Психология понимания мира человека. Москва: Институт психологии РАН. Зоткин, Н. В. (авт.-сост.). (2007). Основы психодиагностики: учебно-методический комплекс для специальности 030301.65 «Психология». Самара: Универс групп.

Калина, Н. Ф. (1998). Вопросник самоактуализации личности. Журнал практического психолога, 1, 65-75.

Корнилова, Т. В., Чумакова, М. А., Корнилов, С. А. и Новикова, М. А. (2010). Психология неопределенности: единство интеллектуально-личностного потенциала человека. Москва: Смысл.

Куницына, В.Н.и Юмкина, Е. А. (2012). Семейный уклад в социально-психологическом аспекте. Современные проблемы науки и образования, 4.

Леонтьев, Д. А. (2013). Личностное изменение человеческого развития. Вопросы психологии, $3,67-80$.

Леонтьев, Д. А., Осин, Е. Н. и Луковицкая, Е. Г. (2016). Диагностика толерантности к определенности: шкалы Д. Маклейна. Москва: Смысл.

Моросанова, В. И. и Аронова, Е. А. (2007). Самосознание и саморегуляция поведения. Москва: Институт психологии РАН.

Нартова-Бочавер, С. К. (2014). Новая версия опросника «Суверенность психологического пространства - 2010». Психологический журнал, 35(3), 105-119. 
ПРОСКУРЯковА Е. А.

СУБЪЕКТИВНАЯ ОЦЕНКА МЕСТ ЖИТЕЛЯМИ САНКТ-ПЕТЕРБУРГА

Российский психологИчЕский жУРнАл, 2020, Т. 17, № 2, 36-57. doi: 10.21702/rpj.2020.2.3

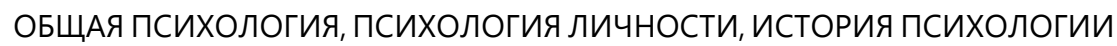

Нартова-Бочавер, С. К., Бочавер, К. А. и Бочавер, С. Ю. (2011). Жизненное пространство семьи: объединение и разделение. Москва: Генезис.

Никишина, В. Б. и Василенко, Т. Д. (2004). Психодиагностика в системе социальной работы: Учеб. пособие для студ. высш. учеб. заведений. Москва: ВЛАДОС-ПРЕСС.

Проскурякова, Е. А. (2016). Исследование в рамках магистерской диссертации «Образ территориального пространства в субъективной картине мира жителей Санкт-Петербурга». В Сборник материалов конференции «Ломоносов 2016». Секция «Социальная психология: проблемы исследования личности». Доступ 17 сентября 2019, источник https://lomonosovmsu.ru/archive/Lomonosov 2016/data/8508/uid110210 report.pdf

Проскурякова, Е. А. и Яничева, Т. Г. (2016). Образ территориального пространства в субъективной картине мира жителей Санкт-Петербурга. В О. Ю. Стрижицкая (ред.), Психология XXI века: российская психология в контексте мировой науки. Материалы международной научной конференции молодых ученых (с. 123-124). Санкт-Петербург: Скифия-принт.

Райгородский, Д. Я. (ред.-сост.). (2001). Практическая психодиагностика. Методики и тесты. учебное пособие. Самара: БАХРАХ-М.

Резниченко, С. И. (2014). Привязанность к месту и чувство места: модели и феномены. Социальная психология и общество, 5(3), 15-27.

Шилин, В. В. (2011). Архитектура и психология. Краткий конспект лекций. Нижний Новгород: Нижегород. гос. архит.-строит. ун-т.

Шиняева, О. В., Ахметшина, Е. Р. и Клюева, Т. В. (2017). Удовлетворенность жильем как идентификатор качества жизни в регионе. Logos et Praxis, 16(4), 64-76. doi: 10.15688/lp.jvolsu.2017.4.7

Штейнбах, Х. Э. и Еленский, В. И. (2004). Психология жизненного пространства. СанктПетербург: Речь.

Эткинд, А. М. (1983). Цветовой тест отношений: Метод. рекомендации. Ленинград: Ленинградский науч.-исслед. психоневрол. ин-т им. В. М. Бехтерева.

Al-Barrak, L., \& Kanjo, E. (March, 2013). NeuroPlace: Making sense of a place. In AH '13: Proceedings of the 4th Augmented Human International Conference (pp. 186-189). doi: $10.1145 / 2459236.2459267$

Al-barrak, L., Kanjo, E., \& Younis, E. M. G. (2017). NeuroPlace: Categorizing urban places according to mental states. PLOS ONE, 12(9), e0183890. doi: 10.1371/journal.pone.0183890

Ardoin, N. M., Gould, R. K., Lukacs, H., Sponarski, C. C., \& Schuh, J. S. (2019). Scale and sense of place among urban dwellers. Ecosphere, 10(9), e02871. doi: 10.1002/ecs2.2871

Ellard, C. (2015). Places of the heart: The psychogeography of everyday life. New York: Bellevue Literary Press.

Glaeser, E. (2011). Triumph of the city: How urban spaces makes us human. Macmillan.

Hadavi, S., Kaplan, R., \& Hunter, M. R. (2018). How does perception of nearby nature affect multiple aspects of neighbourhood satisfaction and use patterns? Journal Landscape Research, 43(3), 360-379. doi: 10.1080/01426397.2017.1314453

Hall, P. (2014). Cities of tomorrow: An intellectual history of urban planning and design since 1880. Wiley Blackwell.

Kasemets, K., Rammo, A., \& Palang, H. (2019). Turning a landscape into a suburban community and the realization of a sense of place. Cities, 88, 37-47. doi: 10.1016/j.cities.2019.01.012

Keedwell, P. (2017). Headspace: The psychology of city living. Aurum Press.

Korpela, K. M. (1989). Place identity as a product of environmental self-regulation. Journal of Environmental Psychology, 9(3), 241-256. doi: 10.1016/S0272-4944(89)80038-6 
ПРОСКУРЯКОВА Е. А.

СУБЪЕКТИВНАЯ ОЦЕНКА МЕСТ ЖИТЕЛЯМИ САНКТ-ПЕТЕРБУРГА

РОССИЙСКИЙ ПСИХОЛОГИЧЕСКИЙ ЖХРнАл, 2020, Т. 17, № 2, 36-57. doi: 10.21702/rpj.2020.2.3

Montgomery, C. (2015). Happy city: Transforming our lives through urban design. Penguin.

Mukherjee, M. (2019). View of a city: An immersive history of Kolkata via camera-eye. South Asian History and Culture, 10(4), 443-469. doi: 10.1080/19472498.2019.1694622

Newman, K. P., \& Brucks, M. (2016). When are natural and urban environments restorative? The impact of environmental compatibility on self-control restoration. Journal of Consumer Psychology, 26(4), 535-541. doi: 10.1016/j.jcps.2016.02.005

Şentürk, A., \& Gülersoy, N. Z. (2019). Aidiyet, kent kimliği ve kentsel koruma etkileşimi bağlamında kullanıcı sürekliliğinin irdelenmesi: Kadıköy Moda örneği [Investigation of user continuity in the context of the sense of belonging, urban identity and urban conservation interaction: The case of Kadıköy-Moda]. Megaron, 14(1), 145-159. doi: 10.5505/megaron.2018.71676

Zabetian, E., \& Kheyroddin, R. (2019). Comparative evaluation of relationship between psychological adaptations in order to reach thermal comfort and sense of place in urban spaces. Urban Climate, 29. doi: 10.1016/j.uclim.2019.100483

Конфликт интересов отсутствует 